\title{
Cognitive Strategies for Teaching Reading in Primary School Teacher Training Curriculum in Vietnamese Context
}

\author{
Nguyen Thi Thu Van \\ Faculty of Foreign Languages \\ Sai Gon University \\ Ho Chi Minh city, Vietnam \\ Dang Quynh Lien \\ Faculty of Foreign Languages \\ Sai Gon University \\ Ho Chi Minh city, Vietnam
}

\author{
Ly Tuan Phu \\ Faculty of Foreign Languages \\ Lac Hong University \\ Bien Hoa city, Vietnam \\ Nguyen Pham Phuong Khanh \\ Faculty of Foreign Languages \\ Sai Gon University \\ Ho Chi Minh city, Vietnam
}

\begin{abstract}
This study aims to explore the effectiveness of cognitive reading strategies in primary school teacher training curriculum. Designed under the paradigm of a quasi-experimental research with the participation of an experimental and a control group, the current study seeks to investigate the impact of cognitive strategies training on students' reading comprehension. Findings from the study showed that cognitive strategies training incorporated into a primary school teacher training course could improve pre-service teachers' reading performance. It is concluded that students need more time and practice so that they can use their new strategies automatically at the procedural stage.
\end{abstract}

Keywords:- Cognitive strategies, Teaching Reading, Teacher Training, Curriculum.

\section{INTRODUCTION}

A number of researchers have investigated the ways "good language learners" successfully employed learning strategies in order to demystify the positive effects of learning strategies and draw out "good lessons" to help low performers in second language learning (Flavell, 1979; Griffiths, 2008). Among these lessons, strategy use can be considered as one of the prominent lessons. Regarding Vietnamese contexts, the investigation into the relationship of learning strategies with second language learning has been scattered. There has not been much research conducted to investigate the effects of cognitive strategies on reading, especially in the teacher training programs. With the aim of improve the quality of teacher training curriculum at the investigated teacher training institution, this study tries to answer the following question: "To what extent do cognitive strategies of teaching reading impact pre-service teachers' reading performance?".

\section{LITERATURE REVIEW}

\section{A. Reading comprehension}

A comprehensive definition of reading is proposed by Williams and Atkins (2009) that a full comprehension of the text means that readers can connect the main ideas of the text. As readers can provide meaningful answers to comprehension questions, which means they can comprehend the text successfully. Comprehension questions can help learner monitor the reading process so that they can achieve the aims outlined in advance (Mudzielwana, 2013). Another element which contributes to reading comprehension is vocabulary (Shieh \& Freiermuth, 2010). At the first glance, one may believe that learners who know the meaning of all lexical items are expected to comprehend the texts successfully. In a similar vein, Harmer (2001) in his definition of reading stresses students' ability of decoding the meaning from the text. However, good ability of decoding does not necessarily result in high reading comprehension. In fact, readers may decode the text correctly but are unable to comprehend the text (Williams \& Atkins, 2009).

Harmer (2001) classified reading into two broad types: extensive and intensive reading. The main feature that helps distinguish extensive from intensive reading is students' choice of reading materials. As for extensive reading, students have the right to choose for themselves the materials to read, which is encouraged by their teachers. As for intensive reading, the materials for reading are chosen in advance. To develop the balance of two kinds of reading, students should be involved in two kinds of reading in order to improve their reading skills.

Along with reading strategies, students' background knowledge can contribute greatly to reading comprehension (Learned, Stockdill \& Moije, 2011). To construct the meaning of the reading text, students can activate their preknowledge relating to the topics of the text to smooth their reading comprehension. Students' background knowledge can be the knowledge relating to the language of the text, 
students' skills of reading text, and so on. In many cases, readers' pre-knowledge can equip students with the necessary information relating to the topics of the text. However, one major issue is that this pre-knowledge is complex and diverse among the students. Regarding students' background knowledge, Phakity (2006) pointed out a number of factors that affect reading comprehension including learners' language competence, personal factors, and reading tests.

Relating to the taxonomies of reading comprehension, Anderson (2003) provided a diagram of reading comprehension which is made up from 4 main elements: reading strategies, reading texts, the fluency, and the way readers constitute the act of reading. The author went further to emphasized the importance of background knowledge in reading. In his opinion, to achieve the full comprehension, students need to orchestrate their background knowledge and the information from the text.

\section{B. Characteristics of good $L 2$ readers}

Wong and Nunan (2011) argued that at least a single strategy lies in every single task even though learners are not aware of this. The significant difference is that good learners are aware of the strategies needed in a task and know how to orchestrate the strategies to achieve the goals of the task while poor learners seem to have great difficulties in doing that. There is a consensus that good readers are better at using strategies than poor readers. One possible explanation is that good readers are clear about what to do to overcome the challenges occurring during their reading process (Anderson, 2003). Thus, they know what strategies to employ in order to reach the meaning of the text. Indeed, there is abundant evidence that strategies possess a strong relationship with reading comprehension. According to Chamot (2004), there has been a much more apparent relationship between language learning strategies and students' proficiency. In a similar vein, Lai (2009) from his study conducted in Taiwan concluded that students' level is related to the use of leaning strategies. He claimed that the students' proficiency level well match with particular kinds of strategies.

Klinger, Vaughn and Boardman (2007) pointed out the following traits of good L2 readers:

$>$ the ability to read quickly and correctly

$>$ establishing what to achieve before reading

$>$ pay attention to the layout of the text

$>$ Checking their progress constantly during the reading process.

$>$ visualize notes and summaries in their mind

$>$ predict, monitor their predictions, and self-evaluate them

$>$ highlight the main points of a reading text and bring them into their learning

$>$ draw inferences from the text

$>$ using their visualization to better their performance
With the good use of the strategies mentioned above, good readers can bridge the cohesion gaps more easily compared with their counterparts in reading. In contrast, poor readers tend to lack motivation, metacognitive strategies, vocabulary, and pre-knowledge of the topics. In addition, they are likely to process the input given in an ineffective way. All of these factors are bound to create blockages in the way to a full reading comprehension. Anderson (2003) mentioned that strategies are one of the four main factors of reading comprehension. Hence, identifying specific strategies can help poor readers to catch up with good readers. However, the coexistence of many strategies during reading process can challenge researchers' efforts in isolating the specific strategies that make great contribution to reading comprehension. Hence, it is safe to conclude that different kinds of strategies may have different degrees of impact on students' reading proficiency.

Ghafounia (2014) shared one similar insight that learning strategies can smooth students' reading comprehension. Hence, it is essential to recognize the impacts of specific strategies on students' reading comprehension. Meanwhile, Graham (1997) concluded that the main strategies which are employed by effective students are metacognitive strategies. This finding concurs with Cohen' (2011) conclusion that learners may use different kinds of strategies to help them comprehend the text but metacognitive strategies are the most effective ones. Apart from the kind of strategies favored by the good readers, Agor (2014) confirmed that good readers are able to make good choice of strategies compared to poor readers. This is true as high-performance readers are aware of which strategies to use and then able to make wise choice to comprehend the text.

Another theme which is carefully examined by a number of researchers is the correlation between the frequency of strategy use and students' performance. In general, high frequency of using specific strategies which leads to greater performance in second language learning can be found in such studies. The study conducted by Chamot (2005) revealed that good language learners have a higher frequency of using metacognitive strategies than low performance learners. As for the context of strategy use, Liynaga (2012) argued that students tend to show a higher frequency of using strategies in the contexts outside the classroom. Perhaps, this is could be explained by the fact that students have more time for their reading than the limited time resources in the context. Thus, they have greater chance to select, monitor, evaluate, and revise the strategies to achieve their goals of reading. Zare-ee (2007) argued that strategy serves as one of the prominent factors that lead to success. Especially, it can be noted that the ways readers use strategy significantly affects the reading comprehension. The study conducted by Zare-ee (2007) revealed that successful and unsuccessful readers differ in the frequency of strategy use. In other words, successful readers showed high frequency in terms of strategy use which leads to their success in reading performance. 


\section{Cognitive strategies for reading}

Mc. Keown and Beck (2009) defined reading as a "a complex mental process with various interacting sub processes" (p. 8). Thus, there is a cognitive process and further processes taking place in students' mind when they are engaged in reading. This concept of reading highlights both cognitive and metacognitive functions of reading and the complexity of reading process. This conclusion is in line with Williams and Atkins' (2009) viewpoint on the role of metacognitive and cognitive strategies in reading comprehension. The two authors indicated that these two specific strategies play a pivotal role in boosting students' reading performance. Another viewpoint of these cognitive processes is proposed by Mikulecky (2009). The author claimed that these cognitive processes can be defined as reading skills that readers employ to comprehend the text.

Findings from previous research have thrown light on the relationship between two particular kinds of strategies, metacognitive and cognitive strategies, and students' performance. Findings from Lai's (2009) study in Taiwan noted that high performance students show a high frequency of using cognitive and metacognitive strategies while low performance students tend to use more social and memory strategies. In the context of metacognitive strategies, one of the main findings is that planning and monitoring are used frequently by more proficient learners. Hence, the researcher concluded that students' level is related to the strategies they choose. In a similar vein, Liu and Chen (2014) shared the same conclusion that the frequency of strategy use is related to learners' anxiety in language learning. The conclusion was drawn from their study in Taiwanese contexts with the participation of 212 fifth- and sixth-grade students. Liu and Chen (2014) stated that students' level of anxiety has a significant relationship with the choice of strategies to ease the difficulties in learning. Metacognitive strategies were at the highest frequency for students in mid-anxiety level.

Oxford (1990) identified and divided cognitive strategies in second language learning as follows:

$>$ Practicing

$>$ Reviewing and sending messages

$>$ Analyzing and reasoning

$>$ Creating structure for input and output

Oxford's taxonomy has not been completely acknowledged by experts in the field. In fact, there has not been a consensus on the classifications of language learning strategies. Commenting on the classifications of direct and indirect strategies, Rubin (1987) noted that metacognitive strategies are direct strategies while Oxford (1990) in her own taxonomy believed that metacognitive strategies are indirect strategies. Such diverse viewpoints on the impact of such kind of strategies is likely to lead to diverse taxonomies of strategies. In addition, Ellis (1994) in his review of literature in the field of strategies pointed out particular perspectives of strategies that cause the diversity among those taxonomies.
D. Metacognitive versus cognitive strategies in second language teaching and learning

Metacognition is broadly defined as the cognition about cognition. The definition shows that cognition occurs first and then metacognition takes place next. In a similar vein, Efklides (2006, p.5) defined metacognitive skills as "procedural knowledge", the knowledge helps the learner to monitor their cognition. Thus, it is generally accepted that metacognition has an executive function over cognition. However, this relationship is "complicated" (Phaekity, 2006, p.50). Hence, more works are needed to lift the mysterious veil of this relationship.

Meanwhile, Klinger, Vaugh, and Boardman (2007) defined metacognition as "thinking about thinking" (p. 11). The authors noted that metacognition has the power over cognition as it directs cognitive process. Liu and Chang (2013) conducted a study with the participation of 163 first year students in Taiwan to examine the relationship between language strategy use and academic-self-concept. Findings from the study revealed that students with high academic self-concept use more metacognitive strategies than students with low academic-self-concept. Hence, there is a direct relationship between cognitive and metacognitive strategies with academic self-concept.

Researchers in the field of learning strategies agree that metacognitive strategies possess the executive functions over cognitive strategies (Klinger, Vaugh, and Boardman, 2007). Purpura (1990) in his definition drawn from previous literature in the field of metacognitive strategy use highlighted its "self-management or executive capacity' (p. 6). Purpura stated that metacognitive strategies possess the function of controlling cognitive strategies. Meanwhile, Phaekity (2006) in his definition of metacognitive strategies highlighted that "metacognitive strategies are the test-takers' deliberate mental behaviors for directing and controlling their cognitive strategy processing for successful performance" (p.30). From this definition, it can be inferred that both metacognitive and cognitive strategies take place at the same time during learners' learning process. Drawing on this, Phaekity (2006) argued that metacognitive and cognitive strategies do not need to take place independently of each other. In contrast, the two kinds of strategies are better viewed as "two interactive facets of one mental process (pp. 47-48). Metacognitive strategies involve the processes of planning, monitoring and evaluating of other strategies in each taxonomy. Similarly, Veenman, Van Hout -Wolters, and Afflerbach (2006) mentioned the intertwined relationship between metacognitive and cognitive strategies via using the example of Comte's paradox; one person cannot split himself into two persons, of whom one person is carrying cognitive activities while the other oversee that person. This paradox proves one thing that the use of metacognitive strategies cannot occur independently of the use of cognitive strategies and via versa. The fact that metacognitive strategies cannot be disentangled from cognitive strategies leads the viewpoint that some strategies can be considered metacognitive or cognitive strategies or both (Williams and Atkins, 2009). 


\section{METHODOLOGY}

\section{A. Research site and participants}

Two classes with a total of 28 students chosen on convenience principle at a teacher training institution in Vietnam joined this study. There are 16 and 18 students in experimental and control group respectively. The 11-week strategy training course (4 class hours per week) was designed based on reading materials that require cognitive reading strategies.

As to the curriculum, students who joined the research had a course of 11 weeks for all the subjects. They had to take reading lessons in the evening class form 5.30 p.m. to 8.30 p.m. once a week. The textbook used for this subject is Market Leader Intermediate previously chosen by the Faculty. A total of 11 Reading Lessons are allocated for 11 weeks. Particular kinds of cognitive strategies were integrated into each lesson.

\section{B. Data collection}

\section{Pre and posttest}

Before embarking on administering the pre- and posttest, a detail description of the final reading test at the research site is necessary to support the choice of the tests. The level, pre-intermediate level, of the test is the same with the level of the textbook used in the classroom. The total items of this reading test are 40 . Time allocated for the test is 90 minutes. Students are not allowed to use their dictionary in the exam.

\section{Questionnaire}

A questionnaire consisting of 48 items on metacognitive and cognitive strategies was designed to investigate students' use of the two kinds of strategies in reading. The contents of the items found in the questionnaire were mainly drawn from the literature review. The questionnaire was administered to 16 students in the experimental group shortly after the end of the training course. All the respondents were allotted 25 minutes to answer the questionnaire right in the classroom. The researcher was in the classroom to help them sort out the ambiguity, clarify the items, and avoid misunderstandings. Only the cognitive strategies part is covered in this report.

\section{Semi-structured interview}

The semi-structured interview is to investigate students' acquisition of strategy learning and their perceptions toward the strategy training course. The contents of metacognitive and cognitive strategy training are then checked in closed- ended questions. Since students' opinions and attitudes towards the training course are diverse, a much more flexible and open tool is required. In this case, open-ended questions meet those requirements as the researcher can ask the respondents for further clarifications. The semi-structured interview which was conducted three days after the end of the course as students' minds are still fresh after the strategy training course. The respondents were allocated about 10 minutes to answer all the questions in the interview. More time could be allocated in case clarifications were needed.

\section{FINDINGS AND DISCUSSION}

\section{A. Impact of cognitive reading strategies}

As can be seen from the table below, the minimum of the pretest scores of the experimental group is 4.57 while it is 5.14 with respect to the control group. As for the maximum score of the pre- test, both the two groups reached the maximum score of 8.57. Also, from the table, the mean of pretest for experimental group (6.75) is slightly higher than the mean score of the control group (6.51).

\begin{tabular}{|c|c|c|c|c|c|c|c|}
\hline \multicolumn{2}{|c|}{} & Count & Mean & Minimum & Maximum & Column N \% \\
\hline Class & Experimental & Pretest & 16 & 6,75 & 4,57 & 8,57 & $47,1 \%$ \\
\cline { 2 - 7 } & Control & Pretest & 18 & 6,51 & 5,14 & 8,57 & $52,9 \%$ \\
\hline
\end{tabular}

Table 1:- The means of pretest score of control and experimental group

An independent-samples t-test was used to investigate levels of the two groups in terms of reading performance before the treatment.

The table below highlights that the means of two groups did not vary as sig $=0.358$ which is lower than $\mathrm{p}$ value $(\mathrm{p}=0.05)$, the null hypothesis that there is no difference in means of the pre-test score could not be rejected. Thus, it can be inferred from non-parametric t-test that the means of the two groups are the same which leads the conclusion that the levels of the two groups before the treatment did not vary much. This conclusion lays a firm bridge for the comparison after the treatment. 
ISSN No:-2456-2165

\begin{tabular}{|c|c|}
\hline \multicolumn{2}{|c|}{ Test Statistics $^{\mathbf{a}}$} \\
\hline \multicolumn{1}{|c|}{ Pretest } \\
\hline Mann-Whitney U & 117,500 \\
\hline Wilcoxon W & 288,500 \\
\hline Z &,- 919 \\
\hline Asymp. Sig. (2-tailed) &, 358 \\
\hline Exact Sig. [2*(1-tailed Sig.)] &, $365^{\text {b }}$ \\
\hline a. Grouping Variable: Class \\
\hline b. Not corrected for ties. \\
\hline
\end{tabular}

Table 2:- the non-parametric t-test of pretest scores

In the posttest, statistically significant difference between the experimental and control group was recorded. Both the minimum and maximum score of the experimental group are higher than control group. Also, the mean score of the posttest of the experimental group is higher than the mean score of the control group. It can be inferred from the table above that there is difference between the two groups in terms of the score of the post test. As for the same posttest, the students in the experimental group performed better and achieves the means score of 7.34 while the members of the control group only completed the posttest with the means of 6.38. The difference of the post test score between the two groups is $0.96(7.34-6,38=0,96)$ which accounts 13 percent of the experimental group's mean $(0.96$ / 7.34) and 15 percent of the control group's mean. In addition, it is worth noting that the experimental group exceled the control group at both the minimum and maximum score of the post test, 5.12 and 9.71 respectively.

\begin{tabular}{|c|c|c|c|c|c|c|c|}
\hline \multicolumn{2}{|c|}{} & Mean & Minimum & Maximum & Median & Standard Deviation \\
\hline \multirow{2}{*}{ Class } & Experimental & Posttest & 7,34 & 5,12 & 9,71 & 7,36 & 1,44 \\
\cline { 2 - 8 } & Control & Posttest & 6,38 & 4,85 & 8,28 & 6,21 & 1,01 \\
\hline
\end{tabular}

Table 3:- description of the posttest scores

Sig value is 0.043 which is lower than p-value set at 0.05. This mean the null hypothesis that there is no difference of the mean scores between experimental and control group can be rejected. The difference is a statistical significance.

\begin{tabular}{|c|c|}
\hline \multicolumn{2}{|c|}{ Test Statistics ${ }^{\text {a }}$} \\
\hline Posttest \\
\hline Mann-Whitney U & 85,500 \\
\hline Wilcoxon W & 256,500 \\
\hline Z & $-2,024$ \\
\hline Asymp. Sig. (2-tailed) &, 043 \\
\hline Exact Sig. [2*(1-tailed Sig.)] &, $042^{\text {b }}$ \\
\hline a. Grouping Variable: Class & \\
\hline b. Not corrected for ties. \\
\hline
\end{tabular}

Table 4:- the non-parametric t-test of the posttest scores

\section{B. Students' perceptions on cognitive strategies for reading}

As for the first item related to making a note of what they can understand from the text, the number of students who showed a high frequency $(62.75 \%)$ of using this strategy outnumbered those who had a lower frequency $(37.5 \%)$ of using it. This informs that making notes is a useful strategy for the majority of the students. With inference to the next item of highlighting, no student showed the lowest level (never) of using this strategy. 6.5\% percent of the students reported that they sometimes used this strategy in their reading, which was outnumbered by students who showed high frequency of using this strategy. In deed, $31.25 \%$ and $37.5 \%$ of the students answered that they often and usually used this strategy respectively. More interestingly, $25 \%$ of the students showed the highest level of using it. With respect to building connections of main ideas in their minds, the students who highly used this strategy excelled those who sometimes $(12.5 \%)$ used it in terms of frequency. Though this strategy is hard to observe, a large number of students reported a high frequency of using it. In a similar vein, the number of students who never and sometimes spent more time on difficult questions was outnumbered by those who had a higher frequency of doing such. $50 \%$ of the students reported they often spent more time on difficult items while $25 \%$ of the students usually took the same course of action. $6.25 \%$ of the students always used this in their reading process.

Reorganizing the text once more time in their own ways can help students better comprehend the text, which explained $75 \%$ of the students favored this strategy and used it at a high frequency, leaving $25 \%$ of the students sometimes used this strategy.

The most successful strategy that students all agreed is using context to guess the meaning of new words. All students reported high frequency of using this strategy. 
With respect to the next items of repeating the main ideas of the text in their mind, a small percent of students $(18.75 \%)$ answered that they sometimes and never did this. Meanwhile, $31.25 \%$ and $50 \%$ of the students confirmed that they sometimes and usually repeated the main ideas of the text in their minds to help them better comprehend the text.
As for the next item, it is hard to decide whether marking the parts that students completely understood is an effective strategy or not in this study as the percent of the students who had low frequency $(50 \%)$ equals the percent of the students who had high frequency of using this strategy $(50 \%)$.

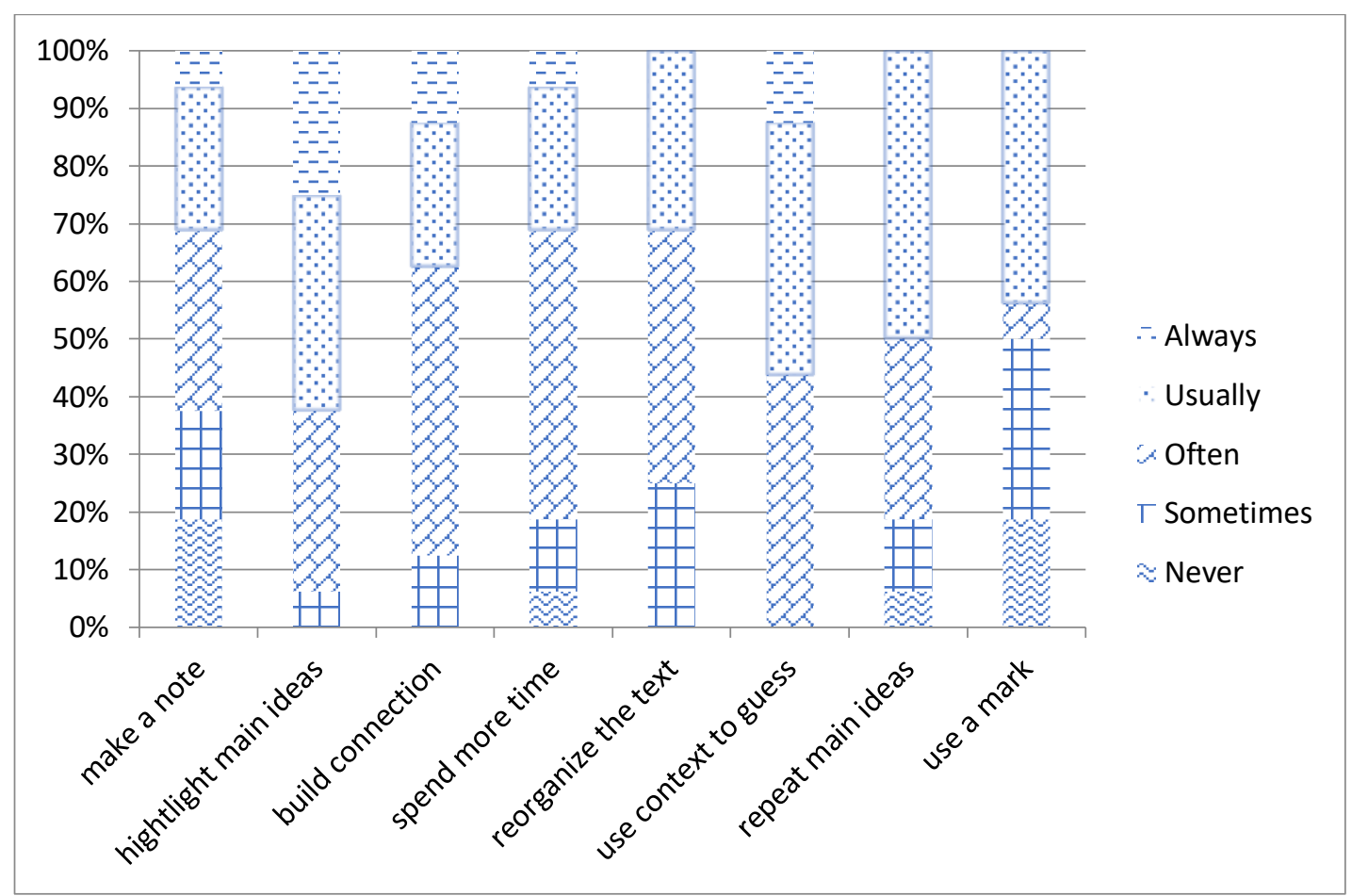

Fig 1:- Result of Memory strategies from students' questionnaires

In short, students generally showed a high frequency of using nearly all the strategies belonging to memory strategy. Among them, highlighting main ideas, building connections of main ideas in the mind, spending more time on difficult question are successful strategies. Using contexts to guess meaning of the new words is the most successful strategy. As for the strategy of using marking, more research is needed to investigate this.

\section{Students'feedback on cognitive strategies for reading}

\section{Advantages of explicit cognitive strategies training}

Most participants agreed that the training course with the integration of reading strategies is effective in general. Under the effectiveness of the course, the students can achieve improvements in terms of vocabulary extension, strategies acquisition, reading speed, knowledge in business "I have learned more business vocabulary. In addition, I have learned more about the skills of scanning the whole text, sentences and vocabulary. I also learn reading questions first and finding answers for the questions later" (S02). Another student from low performance group stated that: "after this reading course? I think my reading skills have improved a little bit compared with the previous course. My vocabulary has been widened. When I read a text, I could comprehend more" ( $\mathrm{S} 05$ )
They all believed that such training course generally enhanced their reading performance, especially in their preparation for the incoming exam. This can be explained through the fact that the students studying at night probably have higher motivation compared with their counterparts studying in the daytime to pass the reading exam. As students have little time to scrutinize the text, they need some strategies which can help them achieve high performance in reading in a short time, which explains why scanning and guessing answers by reading questions are their favorable strategies. Data from the interviews highlighted the fact that paying greater attention to the strategies that helps them save time and gain high performance in reading. Scanning, skimming and guessing the answers from the questions given seems to meet such growing needs

\section{$>$ Useful strategies}

A large number of strategies grouped in to metacognitive and cognitive strategies are integrated into the course so that students can have a wider choice of strategies to suit their reading needs. Students with different levels showed different choice of strategies introduced. 4 out of 9 participants preferred to read the questions first to guess the answers for the reading questions. A highperformance student suggested that the content of the reading text can be found from the questions given at the 
end of the text, which proves one good reason for such strategy. She went on to mention one interesting idea that students can visualize the answers right in their minds and then search for the answers from the text. In the similar vein, another high-performance student also voiced that students partly grasp the main ideas of a reading text provided that they fully understand the meaning of the questions. Another explanation for choosing this strategy is that the key words found in the reading questions. Highlighting the key words in the questions can help them partly anticipate the content of the reading text and thus select the best answers for the reading questions. Hence, highlighting key words is a strategy closely relating to the strategy of reading questions first before reading the test. The levels of a reading texts in the reading exam also have great impact on students' choice of strategies. For texts with high level of difficulty, students tend to select the strategies that help them read faster but still reach a full comprehension of a text. Scanning, skimming, guessing, highlighting seems to fit these gaps. Strategies such as mind- mapping and translation sued for memorizing and checking the meaning of the text seem not be their favorable strategies for this reason.

\section{$>$ How students develop reading strategies}

More than half of the participants agreed upon one thing that the process of acquiring strategies is hard $(\mathrm{r}=$ $0.55)$. In contrast, two students $(r=0.22)$ stated that such process is not difficult. One student from the highperformance group believed that students could gain greater benefits of the successful strategy acquisition. A high percentage of the participants voice that they need more time to practice the strategies, which is fruitful for their process of strategy acquisition. Students are aware that it is hard to use a strategy in the reading process but it is worth the efforts. Indeed, the process of acquiring a strategy is time-consuming and demands great efforts including trials and errors, which can explain why it normally takes students a large amount of time to acquire a new strategy.

One more explanation it is hard for one strategy to become a habit. When students can use a strategy smoothly, it means they have achieved the final stage in the process of strategy acquisition, the declarative stage in the ACT model. One of the participants from the low performance group stated that students often switch back to their old habit of reading. He mentioned that students often feel embarrassed when using a new strategy in their reading process. The experience is new to him and takes him a large amount of time for practice, which causes him embarrassment and stops him from practicing new strategies.

Besides, one student from low performance group indicated that she often concentrates too much on new vocabulary appearing in the texts. She can avoid the temptation of looking up the meaning of every new word though she is aware that a dictionary is now allowed in the examination room.
Only 2 out of 9 students claimed that the process of acquiring a strategy is not as hard as it is widely believed: "I think the process is not difficult. The problem is that every student needs to change their habit. They often read the texts in their own ways without paying attention to the strategies. The students should care more about the strategies. They should use the strategies more frequently until they can form good habits of using them." (S09).

This student from high performance group suggested that students should change their habits when using a strategy and frequently use the strategy at a high degree until they are able to use it automatically.

\section{CONCLUSION}

The current study concluded that teaching students cognitive reading strategy can result in students' higher performance in reading. This highlights one fact that the researcher succeeded in integrating learning strategies into the reading course to some extent. In addition, data analysis indicates that the majority of the students showed a high degree of approval and positive attitudes towards the strategy training course.

This study also has some important implications for primary school teacher training programs. Firstly, most of the students already possess some basic knowledge of learning strategies. They already had some practice of strategies in their second language learning. As for reading, they already know and use strategies in reading such as skimming, scanning, highlighting keywords, and so on. These familiar kinds of strategies could be extended by providing more information about them and more practice so that they can be used without any pause by students. However, students' knowledge of strategies as mentioned is often just at the basic level and not systematic. Hence, it is vital for teachers to provide them with comprehensive and systematic taxonomy of learning strategies to help them widen their knowledge of learning strategies. In addition, teachers should be aware that the different learning strategies can yield different results. Some strategies that students can see their effectiveness while other strategies students need a long practice to be fully aware of their benefits. Some strategies that students can easily see the results of these strategies such as scanning and skimming. However, there are new strategies that students may not know and take a long time of use before they could recognize the effectiveness of those strategies. Clear explanation is needed which requires teachers' comprehensive understanding of the knowledge. Students hence should be clear about the features, functions of each strategy, how to use the strategies integrated into the course for better performance. 


\section{REFERENCES}

[1]. Agor, J. T. (2014). Language-Learner Strategy Instruction and English Achievement: Voices from Ghana. English Language Teaching, 175-191.

[2]. Anderson, N. (2003). Reading. In D. Nunan, Practical English Language Teaching (pp. 67-86). New York: McGraw-Hill/Contemporary.

[3]. Chamot, A. U. (2005). Language learning strategy instruction: current issues and research. Annual Review of Applied Linguistics, 112-130.

[4]. Chamot, A. U. (2004). Issues in Language Learning Stratgy Research and Teaching. Electronic Journal of Foreign Language Teaching, 14-26.

[5]. Cohen, A. (2011). Second Language Learner Strategies. In E. Hinkel, Handbook of Research in Second Language Teaching and Learning Vol II (pp. 681-698). New York: Routledge.

[6]. Efklides, A. (2006). Metacognition and affect: What can metacognitive experiences tell us about the learning process? Educational Research Review 1, 314.

[7]. Ellis, R. (1994). The Study of Second Language Acquisition. Oxford: Oxford University Press.

[8]. Flavell, J. h. (1979). Metacognition and Cognitive Monitoring A New Area of CognitiveDevelopmental Inquiry. American Psychologist, 906911.

[9]. Ghafournia, N. (2014). Language Learning Strategy Use and Reading Achievement. English Language Teaching;, 64-73.

[10]. Graham, S. (1997). Effective Language Learning Positive Strategies for Advanced Level Language Learning Modern Languages in Practice 6. Clevedon: Multilingual Matters.

[11]. Griffiths , C. (2008). Lessons from Good Language Learners. Cambridge: Cambridge University Press.

[12]. Harmer, J. (2001). The Practice of English Language Teaching. Country Harlow: Pearson Education.

[13]. Klingner, J. K., Vaughn, S., \& Boardman, A. (2007). Teaching Reading Comprehension to Students with Learning Difficulties. New York: The Guilford Press.

[14]. Lai, Y.-C. (2009). Language Learning Strategy Use and English Proficiency of University Freshmen in Taiwan. Tesol Quarterly, 255-280.

[15]. Learned, J. E., Stockdill, D., \& Moje, E. B. (20122). Integrating Reading Strategies and Knowledge Building in Adolescent Literacy Instruction. In S. Samuels, \& A. E. Farstrup, What research has to say about reading instruction (4th ed) (pp. 159-185). Newark: International Reading Association.

[16]. Liyanage, I. (2012). "To Be or Not To Be" Metacognitive:Learning EFL Strategically. Electronic Journal of Foreign Language Teaching, 5-25.

[17]. McKeown, M. G., \& Beck, I. L. (2009). The Role of Metacognition in Understanding and Supporting Reading Comprehension*. In D. J. Hacker, J. Dunlosky, \& A. C. Graesser, Handbook of Metacognition in Education (pp. 7-24). New York: Taylor \& Francis.
[18]. Liu, H.-j., \& Chang, C.-h. (2013). A Study on Language Learning Strategy Use and Its Relation to Academic Self-concept: The Case of EFL Students in Taiwan. Journal of Language Teaching and Research, 260-268.

[19]. Liu, H.-j., \& Chen, T.-H. (2014). Learner Differences among Children Learning a Foreign Language: Language Anxiety, Strategy Use, and Multiple Intelligences. English Language Teaching, 1-13.

[20]. Mikulecky, B. S. (2009). Teaching Reading in a Second Language. Pearson ELT.

[21]. Mudzielwana, N. P. (2013). Research-based Teaching Comprehension Strategies: Bridging the Gap. Journal of Language Teaching and Research, 317-327.

[22]. Oxford, R. L. (1990). Language Learning Strategies What Every Teacher Should Know. Boston: HEINLE \& HEINKE PUBPLISHERS.

[23]. Phaekity, A. (2006). Modeling cognitive and metacognitive strategies and their relationships to EFL reading test performance. Melbourne Papers in Language Testing, , 53-95.

[24]. Purpura, J. E. (2009). Learner Strategy Use and Performance on Language Tests: A structural equation modeling approach. Cambridge: Cambridge University Press.

[25]. Rubin, J. (1987). What the "Good Language Learner" Can Teach Us. TESOL Quarterly, 40-51.

[26]. Shieh, W., \& Freiermuth, M. R. (2010). Using the DASH Method to Measure Reading Comprehension. TESOL QUARTERLY, 110-128.

[27]. Williams, J. P., \& Atkins, J. (2009). The Role of Metacognition in Teaching Reading Comprehension to Primary Students. In D. J. Hacker, J. Dunlosky, \& A. C. Graesser, Handbook of Metacognition in Education (pp. 26-42). New York: Taylor \& Francis.

[28]. Wong, L., \& Nunan, D. (2011). The learning styles and strategies of effective language learners. ScienceDirect, 144-163.

[29]. Veenman, M., Van Hout- Wolters, B., \& Afflerbach, P. (2006). Metacognition and learning: conceptual and methodological consideratipns. Metacognition Learning, 3-14.

[30]. Zare-ee, A. (2007). The Relationship between Cognitive and Meta-cognitive Strategy use and EFL Reading Achievement. Journal of Applied Psychology, 105-119. 